\title{
A novel morphological approach to gonads in disorders of sex development
}

\author{
Laureline Lepais ${ }^{1,2}$, Yves Morel ${ }^{2,3}$, Pierre Mouriquand ${ }^{2,4}$, Daniela Gorduza ${ }^{4}$, \\ Ingrid Plotton ${ }^{2,3}$, Sophie Collardeau-Frachon ${ }^{1,2}$ and Frédérique Dijoud ${ }^{1,2}$ \\ ${ }^{1}$ Service d'Anatomie Pathologique, Centre de Biologie et de Pathologie Est, Bron, France; ${ }^{2}$ Université Lyon 1, \\ Lyon, France; ${ }^{3}$ Service d'Endocrinologie Moléculaire et Maladies Rares, Centre de Biologie et de Pathologie \\ Est, Bron, France and ${ }^{4}$ Service de Chirurgie Urologique Pédiatrique, Hôpital Femme Mère Enfant, Bron, \\ France
}

\begin{abstract}
Disorders of sex development are defined as congenital conditions with discordance between the phenotype, the genotype, the karyotype, and the hormonal profile. The disorders of sex development consensus classification established in $\mathbf{2 0 0 5}$ are mainly based on chromosomal and biological data. However, histological anomalies are not considered. The aims of this study were to define the specific pathological features of gonads in various groups of disorders of sex development in order to clarify the nosology of histological findings and to evaluate the tumor risk in case of a conservative approach. One hundred and seventy-five samples from 86 patients with disorders of sex development were analyzed following a strict histological reading protocol. The term 'gonadal dysgenesis' for the histological analysis was found confusing and therefore excluded. The concept of 'dysplasia' was subsequently introduced in order to describe the architectural disorganization of the gonad (various degrees of irregular seminiferous tubules, thin albuginea, fibrous interstitium). Five histological types were identified: normal gonad, hypoplastic testis, dysplastic testis, streak gonad, and ovotestis. The analysis showed an association between undifferentiated gonadal tissue, a potential precursor of gonadoblastoma, and dysplasia. Dysplasia and undifferentiated gonadal tissue were only encountered in cases of genetic or chromosomal abnormality ('dysgenesis' groups in the disorders of sex development consensus classification). 'Dysgenetic testes', related to an embryonic malformation of the gonad, have variable histological presentations, from normal to streak. Conversely, gonads associated with hormonal deficiencies always display a normal architecture. A loss of expression of AMH and $a$-inhibin was identified in dysplastic areas. Foci of abnormal expression of the CD117 and OCT4 immature germ cells markers in dysplasia and undifferentiated gonadal tissue were associated with an increased risk of neoplasia. This morphological analysis aims at clarifying the histological classification and gives an indication of tumor risk of gonads in disorders of sex development.

Modern Pathology (2016) 29, 1399-1414; doi:10.1038/modpathol.2016.123; published online 29 July 2016
\end{abstract}

Disorders of sex development are a group of congenital pathologies in which chromosomal, gonadal, or phenotypic sex is discordant. ${ }^{1}$ It is a complex issue with multiple endocrine, biological, surgical, and psychological controversies. As a consequence, risks of cancer and fertility are the main concern. In 2005, an expert meeting held by the Lawson Wilkins Paediatric Endocrine Society and the European Society for Paediatric Endocrinology led to the publication of a consensus statement on the

Correspondence: Dr F Dijoud, MD, Service d'Anatomie Pathologique, Centre de Biologie et de Pathologie Est, 59 Boulevard Pinel, Bron 69500, France.

E-mail: frederique.dijoud@chu-lyon.fr

Received 20 January 2016; revised 9 June 2016; accepted 10 June 2016; published online 29 July 2016 management of disorders of sex development, including a new terminology and a classification based on karyotype, hormonal profiles, and molecular biology. ${ }^{1}$ Since then, it is the reference classification to date. However, the role of gonadal histology was poorly defined in this classification. It is unclear whether correlations exist between this classification and the histology of gonads. Since 2005, new insights have been reported in the histological analysis of gonads in cases of disorders of sex development, ${ }^{2-6}$ but no study to date correlated histological findings with the various etiologic types. Literature in this field is particularly confusing as terminology is variable and inconsistent. In addition, the gonadal tumor risk is highly variable in disorders of sex development, fluctuating between an almost nil risk (46,XX patients with hypervirilization) and a very high one: from $33 \%$ 
Table 1 Histological reading template used for the analysis of gonads

\begin{tabular}{|c|c|}
\hline Type of gonad & Testis, ovary, ovotestis, streak \\
\hline Albuginea & Absence, presence/aspect, epithelial layer \\
\hline Architecture & Normal (regular lobules), abnormal (focal/diffuse) \\
\hline Interstitium & Normal or edematous, fibro-edematous, fibrous, fibroblastic (focal/diffuse) \\
\hline Leydig cells & Presence, absence, hyperplasia \\
\hline Seminiferous tubules & $\begin{array}{l}\text { Morphology: normal (regular), abnormal (irregular/branched), diminished number, prepubertal or pubertal } \\
\text { tubules } \\
\text { Thickness of the lamina of the seminiferous tubules } \\
\text { Germ cells: normal, absence, hypoplasia; topography in the tubule } \\
\text { Presence of calcifications }\end{array}$ \\
\hline Undifferentiated cords & With sex cords cells and/or germ cells \\
\hline Ovarian follicles & Presence, absence \\
\hline Pretumor lesions & Gonadoblastoma, germ cell neoplasia in situ \\
\hline Germ cell tumor & Presence, absence, type \\
\hline Other lesion & (Sertoli cells adenoma, hamartoma...) \\
\hline
\end{tabular}

Table 2 Immunohistochemical study protocol

\begin{tabular}{|c|c|c|c|c|c|c|c|c|}
\hline Antibody & Clone & Dilution & Pre-ttt & HIER & Incubation & Revelation & Chromogenic & Staining \\
\hline Inhibin ( $\alpha$-subunit) & $\begin{array}{l}\text { Monoclonal mouse Ab } \\
\text { Clone R1 SEROTEC } \\
\text { MCA951S }\end{array}$ & $1 / 200$ & CC1 std & $99^{\circ} \mathrm{C}$ & $32 \mathrm{~min}$ & $\begin{array}{l}\text { HRP } \\
\text { Multiplex }\end{array}$ & $\mathrm{DAB}$ & Cytoplasmic \\
\hline $\mathrm{AMH}$ & $\begin{array}{l}\text { Monoclonal mouse Ab } \\
\text { Clone 5/6 ACRIT } \\
\text { AMO5878SU }\end{array}$ & $1 / 20$ & & & & & & Cytoplasmic \\
\hline CD117 & $\begin{array}{l}\text { Polyclonal rabbit Ab } \\
\text { DAKO A4502 }\end{array}$ & $1 / 200$ & & & & & & $\begin{array}{l}\text { Cytoplasmic granular with } \\
\text { membranous enhancement }\end{array}$ \\
\hline OCT4 & $\begin{array}{l}\text { Monoclonal mouse Ab } \\
\text { ROCHE MRQ-10 }\end{array}$ & Ready to use & & & & & & $\begin{array}{l}\text { Nuclear+/ - cytoplasmic } \\
\text { granular }\end{array}$ \\
\hline
\end{tabular}

Abbreviatons: Ab, antibody; CC1 std, (Cell Conditioning Solution, VENTANA Medical System); DAB, 3,3'diaminobenzidine; HIER, heat-induced epitope retrieval; HRP, horseradish peroxidase; Pre-ttt: pre-treatment: 64 min on Ultra-XT BENCHMARK VENTANA. Revelation kit: UltraView ref 700-500 DAB detection VENTANA (ROCHE).

up to $50 \%$ (46, XY gonadal dysgenesis with hypovirilization or germinal mosaicism). ${ }^{2}$ Cools et $a l^{2,7}$ recently identified undifferentiated gonadal tissue as a precursory lesion of gonadoblastoma. The tumor risk of undifferentiated gonadal tissue is yet hard to ascertain. ${ }^{4,8,9}$ Whereas early gonadectomy and feminizing surgery were often recommended in disorders of sex development with a high tumor risk, ${ }^{10}$ the current attitude is to avoid mutilating surgeries in children and to identify more accurately the tumor risk of gonads. This includes close patients' follow-up with ultrasonography or laparoscopy and, for some authors, iterative gonadal biopsies. ${ }^{11}$ This study lists the specific pathological features of gonads encountered in various types of disorders of sex development, assesses their prevalence in the different etiologic groups as well as their respective risks of tumors, and attempts to clarify the terminology used to describe gonads in cases of disorders of sex development.

\section{Materials and methods}

The gonadal samples were collected from a single pathology center (Lyon's Children University
Hospitals) and they were collected over a period of 42 years (1971-2013). The histological study was conducted in two steps by two senior pathologists blinded to any clinical, genetic, and biological data. The first phase was to describe the various histological patterns and to establish a reading protocol according to architectural criteria (Table 1). All slides stained with hematoxylin, eosin, and saffron were reviewed and an immunohistochemical study was performed (Table 2). Patients were then divided into five groups, depending on the genetic, molecular, or hormonal diagnosis, based on the Lawson Wilkins Paediatric Endocrine Society/European Society for Paediatric Endocrinology consensus classification: ${ }^{1}$ group (1): $46, \mathrm{XY}$ disorders of sex development with disorders in hormonal synthesis or action (with two subgroups: 'androgen biosynthesis defect and disorders of anti-Mullerian hormone and anti-Mullerian hormone receptor' and 'defect in androgen action'); group (2): 46,XY disorders of sex development with disorders of gonadal development; group (3): sex chromosome mosaicism/mixed gonadal dysgenesis; group (4): undetermined etiology disorders of sex development including (i) patients with normal karyotype and molecular analysis of the major genes involved in sex 
determination-ie SF1, WT1, SRY, DAX1, SOX9, and sex differentiation-androgen receptor, steroid biosynthesis enzymes, $L H$ and its receptor, $A M H$ and its receptor, and (ii) patients with no biological assessment due to the absence of available DNA or cell-lineage, or for which data were no longer available; group (5): ovotesticular syndrome with a coexistence of ovarian and testicular tissue in the same patient. The term 'ovotestis' was used to describe the coexistence of testicular and ovarian tissue in a single gonad.

Immature or neoplastic germ cell components were detected using OCT4 and CD117 immunomarkers. Germ cell hypoplasia in prepubertal seminiferous tubules was determined using the Nistal score. ${ }^{12}$ Germ cell hypoplasia in pubertal seminiferous tubules was estimated with the Johnsen score. ${ }^{13}$ Germ cell maturation delay was defined by the presence of germ cells with round nuclei and positive OCT4 staining in the lumen of the seminiferous tubules in patients older than 6 months old. ${ }^{14}$ Germ cell neoplasia in situ corresponded to clusters of germ cells replacing spermatogonia ${ }^{15-17}$ and expressing CD117 and OCT4. Undifferentiated gonadal tissue was diagnosed when gonadal tissue containing germ cells was seen outside seminiferous tubules or follicles, randomly distributed in a background of stromal cells or arranged in clusters adjacent to Sertoli or granulosa cells. ${ }^{7}$ Gonadoblastoma was considered when both germ cells and Sertoli-like cells were arranged in clusters with hyaline and often calcified material within their lumens. ${ }^{18}$ A paucicellular form of gonadoblastoma or burnt-out gonadoblastoma ${ }^{4}$ was defined by large calcifications that almost totally replaced the cellular clusters.

All the data were compiled using the Microsoft Excel software, and the analysis of the results was made through cross-tabulations. The criteria of the reading protocol led to the identification of five histological types of gonads: (1) normal gonad (testis or ovary), (2) hypoplastic testis, (3) testis with 'dysplasia', (4) streak gonad, and (5) ovotestis. Additional lesions could be observed in some subtypes (Table 3). The severity of germ cell hypoplasia and 'testicular dysplasia'-mild, moderate, severe-were also identified using architectural features.

\section{Results}

One hundred and seventy-five gonadal samples (biopsies, orchiectomies, terminations of pregnancy) were collected from 86 patients. The histological features of each group are reported in Table 4 . Histological findings and immunostainings of $\alpha$-inhibin and AMH of the different histological subtypes are illustrated in Figure 1. The distribution of gonadal subtypes is presented in Figure 2.

\section{Group 1}

Subgroup 1A: 46,XY disorders of sex development with androgen biosynthesis defect and disorders of anti-Mullerian hormone and anti-Mullerian hormone receptor. This subgroup included 23 samples from 13 patients aged from 2 to 218 months old (Table 4-A1). Etiologies included mutations of 17ßHSD3 (6/13), AMH (4/13), CYP17 (2/13), and StAR (1/13). No patient had iterative biopsies. All gonadal samples were tested (23/23) and harbored similar features on biopsy and surgical specimen; one patient displayed a normal testis on the right side and a testis with moderate germ cell hypoplasia on the left side. Gonads with germ cell hypoplasia increased with the age of the patients: the germ cell count was normal in 6 patients from 2 to 16 months old $(6 / 23,26 \%)$, but in patients over 16 months old all gonads displayed germ cell hypoplasia: moderate from 12 to 26 months old $(9 / 23,40 \%)$ and severe from 34 to 218 months old $(8 / 23,35 \%)$. Two patients had surgery after puberty (161 and 218 months old); their testes were prepubertal or pubertal in aspect, but the seminiferous tubules had a thickened basal membrane, atrophied Sertoli cells, and severe hypospermatogenesis (score of Johnsen $=3$ ). The immunohistochemical study was performed on 12 samples. It underlined a weak but constant expression of $\alpha$-Inhibin and AMH (11/12, 92\%), except in one case ( $A M H$ mutation). Five of 12 cases $(42 \%)$ also displayed germ cell maturation delay (from 14 to 21 months old).

Subgroup 1B: 46,XY disorders of sex development with defect in androgen action. This subgroup of 38 samples from 16 patients aged from 0.7 to 224 months old included cases of $5 \alpha$-reductase mutation (3/16) (Table 4-1B), cases of complete androgen insensitivity syndrome (9/16), and cases of partial androgen insensitivity syndrome (4/16). Bilateral gonadectomy was performed in all patients. Multiple gonadal samples were available in 4 patients (uni- or bilateral biopsy, then bilateral gonadectomy). When both gonads were sampled at the same age $(n=18)$, their aspect was most of the time symmetrical (16/18). The proportion of gonads with germ cell hypoplasia increased with the patients' age: testes appeared normal from 0.3 to 21 months old $(11 / 38,29 \%)$, whereas moderate germ cell hypoplasia was observed from 1 to 85 months old $(7 / 38,18 \%)$, and severe germ cell hypoplasia from 17 to 224 months old (21/38, 53\%). Five patients who had surgery after puberty (170-224 months old) displayed hypoplasia with severe hypospermatogenesis (score of Johnsen = 2 to 3), atrophy of Sertoli cells and thickening of the lamina propria of the seminiferous tubules. When successive samples were performed in the same patient, the number of germ cells decreased over time. Hamartomatous lesions were discovered in patients with complete androgen insensitivity syndrome at puberty and beyond $(3 / 38,8 \%)$. Sertoli cell 
Table 3 Proposal of histological classification of the various types of gonads and additional lesions encountered in disorders of sex development

Immunohistochemical characteristics

Histological subtypes

Normal gonad

Testis: Thick and regular albuginea

Round or oval regular seminiferous tubules

$\alpha$-inhibin +, AMH+

Low-abundance or edematous interstitium

Ovary: Abundant ovarian stroma

Numerous and regular follicles

Hypoplastic testis

Scarcity of seminiferous tubules

Germ cell hypoplasia

Abundant edematous stroma

Dysplasia

Architectural disorganization

Irregular, branched seminiferous tubules

Thin, irregular albuginea

Fibrous interstitium

Streak gonad

Abundant fibroblastic interstitium

Absence of tubule

Absence of follicle

Ovotestis

Coexistence in the same gonad of ovarian and testicular tissues

Additional lesions

Atrophy

Thickening of the lamina propria of seminiferous tubules

Seminiferous tubules of small diameter

Seminiferous epithelium disorganization

Incomplete spermatogenesis

Undifferentiated gonadal tissue

Germ cells within immature sex cords or isolated in the interstitium

Tumor

Gonadoblastoma, germ cell neoplasia in situ, germ cell tumor,

hamartoma, ...

Histological features of dysplasia

Mild dysplasia

Abnormal branching of tubules located under the testicular capsule, separated from the normal area of testis by an edematous gap

Moderate dysplasia

Irregular and thin albuginea, irregular tubules, fibrosis and edema of the interstitial tissue

Severe dysplasia

Absence of albuginea, loss of the lobular pattern, anastomotic tubules, fibrous or fibroblastic interstitium

$\alpha$-inhibin+, AMH+

+/ - germ cell immaturity biomarkers: CD117, OCT4

Progressive loss of expression of $\alpha$-inhibin and AMH in disorganized tubules; absence of expression in severe dysplasia + / - abnormal expression of CD117 and OCT4 of germ cells adenoma or microadenoma also occurred (4/38, $11 \%)$. The immunohistochemical study was performed on 18 samples and displayed a weak but constant expression of $\alpha$-inhibin and AMH. The staining was stronger in case of Sertoli cells (micro) adenoma. One of 18 gonads (6\%) presented with germ cell maturation delay (7-month-old patient). Three of 18 gonads (17\%) which came from older patients (170, 183 months old) contained CD117- and OCT4stained germ cells at the center of seminiferous tubules without features suggestive of germ cell neoplasia in situ. This aspect of persistent immaturity of germ cells could be a 'pre-germ cell neoplasia in situ' as described by Kaprova-Pleskacova et al. ${ }^{19}$

\section{Group 2: 46,XY Disorders of Sex Development with Disorders of Gonadal Development}

This group included 36 samples from 18 patients from 20 gestational weeks +4 days $(20 \mathrm{GW}+4)$ to 204 months old (Table 4-2). One patient went through bilateral gonadal biopsies at the age of 72 months old and a bilateral gonadectomy at 92 months old. Karyotypes were 46,XY (18/18). Gonads in this group were: normal testis $(5 / 36$, $14 \%)$, hypoplastic testis $(12 / 36,33 \%)$, testis with dysplasia: moderate $(4 / 36,11 \%)$, severe $(9 / 36,25 \%)$, and streak (3/36, 8\%). Gonadoblastoma was found in $7 / 36$ cases (19\%), from birth to 17 years old. Massive tumor evolution was observed in $3 / 36$ samples $(8 \%)$. 
Table 4 Histological aspects of gonads encountered in the study groups, based on the reading template

1-46,XY disorders of sex development with disorders in hormonal synthesis or action

1A-46,XY disorders of sex development with androgen biosynthesis defect and disorders of anti-Mullerian

Patients, $\mathrm{n}=13$

hormone and anti-Mullerian hormone receptor Specimen, $\mathrm{n}=23$ (biopsy, $\mathrm{n}=9$; gonadectomy, $\mathrm{n}=14$ ) Comments

\begin{tabular}{|c|c|c|}
\hline Testis & $100 \%(23 / 23)$ & \\
\hline Ovary & $0 \%(0 / 23)$ & \\
\hline \multicolumn{3}{|l|}{ Architecture } \\
\hline Normal & $100 \%(23 / 23)$ & \\
\hline Abnormal & $0 \%(0 / 23)$ & \\
\hline \multicolumn{3}{|l|}{ Seminiferous tubules } \\
\hline Normal & $100 \%(23 / 23)$ & \\
\hline Abnormal & $0 \%(0 / 23)$ & \\
\hline \multicolumn{3}{|l|}{ Germ cells } \\
\hline Normal amount & $26 \%(6 / 23)$ & From 2 to 16 months old \\
\hline Germ cell hypoplasia & $74 \%(17 / 23)$ & From 12 months old \\
\hline \multicolumn{3}{|l|}{ Interstitium } \\
\hline Normal, edematous & $100 \%(23 / 23)$ & \\
\hline Fibroblastic & $0 \%(0 / 23)$ & \\
\hline \multicolumn{3}{|l|}{ Additional criteria } \\
\hline Atrophy & $17 \%(4 / 23)$ & $\begin{array}{l}2 \text { patients after the age of puberty } \\
\text { (161 and } 218 \text { months old) }\end{array}$ \\
\hline Undifferentiated gonadal tissue & $0 \%(0 / 23)$ & \\
\hline Tumor & $0 \%(0 / 23)$ & \\
\hline
\end{tabular}

\begin{tabular}{|c|c|c|}
\hline $\begin{array}{l}1 B-46, X Y \text { disorders of sex development } \\
\text { with defect in androgen action }\end{array}$ & $\begin{array}{c}\text { Patients, } \mathrm{n}=16 \\
\text { Specimen, } \mathrm{n}=38(\text { biopsy, } \mathrm{n}=7 ; \text { gonadectomy, } \mathrm{n}=31)\end{array}$ & Comments \\
\hline Testis & $100 \%(38 / 38)$ & \\
\hline Ovary & $0 \%(0 / 38)$ & \\
\hline \multicolumn{3}{|l|}{ Architecture } \\
\hline Normal & $100 \%(38 / 38)$ & \\
\hline Abnormal & $0 \%(0 / 38)$ & \\
\hline \multicolumn{3}{|l|}{ Seminiferous tubules } \\
\hline Normal & $100 \%(38 / 38)$ & \\
\hline Abnormal & $0 \%(38 / 38)$ & \\
\hline \multicolumn{3}{|l|}{ Germ cells } \\
\hline Normal amount & $29 \%(11 / 38)$ & From 1 week to 21 months old \\
\hline Germ cell hypoplasia & $71 \%(27 / 38)$ & From 1 month old \\
\hline \multicolumn{3}{|l|}{ Interstitium } \\
\hline Normal, edematous & $100 \%(38 / 38)$ & \\
\hline Fibroblastic & $0 \%(0 / 38)$ & \\
\hline \multicolumn{3}{|l|}{ Additional criteria } \\
\hline Atrophy & $26 \%(10 / 38)$ & Patients beyond puberty ( $>14$ years old) \\
\hline Undifferentiated gonadal tissue & $0 \%(0 / 38)$ & \\
\hline \multirow[t]{3}{*}{ Tumor } & Hamartoma $8 \%(3 / 38)$ & $\begin{array}{l}\text { Patients with complete androgen } \\
\text { insensitivity syndrome beyond puberty } \\
(>14 \text { years old })\end{array}$ \\
\hline & Sertoli cell (micro) adenoma 11\% (4/38) & \\
\hline & 'Pre-germ cell neoplasia in situ' $17 \%(3 / 18)$ & Patients beyond puberty ( $>14$ years old) \\
\hline
\end{tabular}

Patients, $\mathrm{n}=18$

2-46,XY disorders of sex development with disorders of gonadal development

\begin{tabular}{lc}
\hline Testis & $100 \%(36 / 36)$ \\
Ovary & $0 \%(0 / 36)$ \\
Architecture & \\
Normal & $47 \%(17 / 36)$ \\
Abnormal & $53 \%(19 / 36)$
\end{tabular}

Comments

Moderate dysplasia 11\% (4/36)

Severe dysplasia $25 \%(9 / 36)$

Streak 8\% (3/36) 
Table 4 (Continued)

\begin{tabular}{|c|c|c|}
\hline $\begin{array}{l}\text { 2-46,XY disorders of sex development } \\
\text { with disorders of gonadal development }\end{array}$ & $\begin{array}{c}\text { Patients, } \mathrm{n}=18 \\
\text { Specimen, } \mathrm{n}=36 \begin{array}{c}\text { (biopsy, } \mathrm{n}=2 ; \text { gonadectomy, } \mathrm{n}=22 \\
\text { autopsy, } \mathrm{n}=12 \text { ) }\end{array}\end{array}$ & Comments \\
\hline \multicolumn{3}{|l|}{ Seminiferous tubules } \\
\hline Normal & $47 \%(17 / 36)$ & \\
\hline Abnormal & $53 \%(19 / 36)$ & \\
\hline \multicolumn{3}{|l|}{ Germ cells (in normal seminiferous tubules) } \\
\hline Normal amount & $14 \%(5 / 36)$ & \\
\hline Germ cell hypoplasia & $33 \%(12 / 36)$ & \\
\hline \multicolumn{3}{|l|}{ Interstitium } \\
\hline Normal, edematous & $47 \%(17 / 36)$ & \\
\hline Fibroblastic & $53 \%(19 / 36)$ & \\
\hline \multicolumn{3}{|l|}{ Additional criteria } \\
\hline Atrophy & $0 \%(0 / 36)$ & \\
\hline Undifferentiated gonadal tissue & $31 \%(11 / 36)$ & \\
\hline \multirow{4}{*}{ Tumor } & Gonadoblastoma 19\% (7/36) & From birth to 204 months old \\
\hline & Dysgerminoma+choriocarcinoma $3 \%(1 / 36)$ & SRY mutation-150 months old \\
\hline & Dysgerminoma 3\% $(1 / 36)$ & SRY mutation-204 months old \\
\hline & Teratoma with somatic-type malignancy $3 \%(1 / 36)$ & $D A X 1$ duplication—151 months old \\
\hline $\begin{array}{l}\text { 3-Sex chromosome mosaicism/mixed } \\
\text { gonadal dysgenesis }\end{array}$ & $\begin{array}{c}\text { Patients, } \mathrm{n}=18 \\
\text { Specimen, } \mathrm{n}=35 \text { (biopsy, } \mathrm{n}=5 ; \text { gonadectomy, } \\
\mathrm{n}=36 ; \text { fetal autopsy, } \mathrm{n}=4)\end{array}$ & Comments \\
\hline Testis & $100 \%(35 / 35)$ & \\
\hline Ovary & $0 \%(0 / 35)$ & \\
\hline \multicolumn{3}{|l|}{ Architecture } \\
\hline Normal & $11 \%(4 / 35)$ & \\
\hline \multirow[t]{4}{*}{ Abnormal } & $89 \%(31 / 35)$ & Mild dysplasia 23\% (8/35) \\
\hline & & Moderate dysplasia 9\% (3/35) \\
\hline & & Severe dysplasia $17 \%(6 / 35)$ \\
\hline & & Streak $40 \%(14 / 35)$ \\
\hline \multicolumn{3}{|l|}{ Seminiferous tubules } \\
\hline Normal & $11 \%(4 / 35)$ & \\
\hline Abnormal & $89 \%(31 / 35)$ & \\
\hline \multicolumn{3}{|l|}{ Germ cells (in normal seminiferous tubules) } \\
\hline Normal amount & $3 \%(1 / 35)$ & \\
\hline Germ cell hypoplasia & $9 \%(3 / 35)$ & \\
\hline \multicolumn{3}{|l|}{ Interstitium } \\
\hline Normal, edematous & $11 \%(4 / 35)$ & \\
\hline Fibroblastic & $89 \%(31 / 35)$ & \\
\hline \multicolumn{3}{|l|}{ Additional criteria } \\
\hline Atrophy & $0 \%(0 / 35)$ & \\
\hline Undifferentiated gonadal tissue & $49 \%(17 / 35)$ & \\
\hline Tumor & Gonadoblastoma 6\% (2/35) & 1 patient (158 months old) \\
\hline $\begin{array}{l}\text { 4-Undetermined etiology disorders of } \\
\text { sex development }\end{array}$ & $\begin{array}{c}\text { Patients, } \mathrm{n}=15 \\
\text { Specimen, } \mathrm{n}=30(\text { biopsy, } \mathrm{n}=11 ; \text { gonadectomy, } \mathrm{n}=15 ; \\
\text { fetal autopsy, } \mathrm{n}=4)\end{array}$ & Comments \\
\hline Testis & $100 \%(30 / 30)$ & \\
\hline Ovary & $0 \%(0 / 30)$ & \\
\hline \multicolumn{3}{|l|}{ Architecture } \\
\hline Normal & $50 \%(15 / 30)$ & \\
\hline \multirow[t]{4}{*}{ Abnormal } & $50 \%(15 / 30)$ & Mild dysplasia 7\% (2/30) \\
\hline & & Moderate dysplasia $3 \%(1 / 30)$ \\
\hline & & Severe dysplasia $13 \%(4 / 30)$ \\
\hline & & Streak $27 \%(8 / 30)$ \\
\hline \multicolumn{3}{|l|}{ Seminiferous tubules } \\
\hline Normal & $50 \%(15 / 30)$ & \\
\hline Abnormal & $50 \%(15 / 30)$ & \\
\hline
\end{tabular}


Table 4 (Continued)

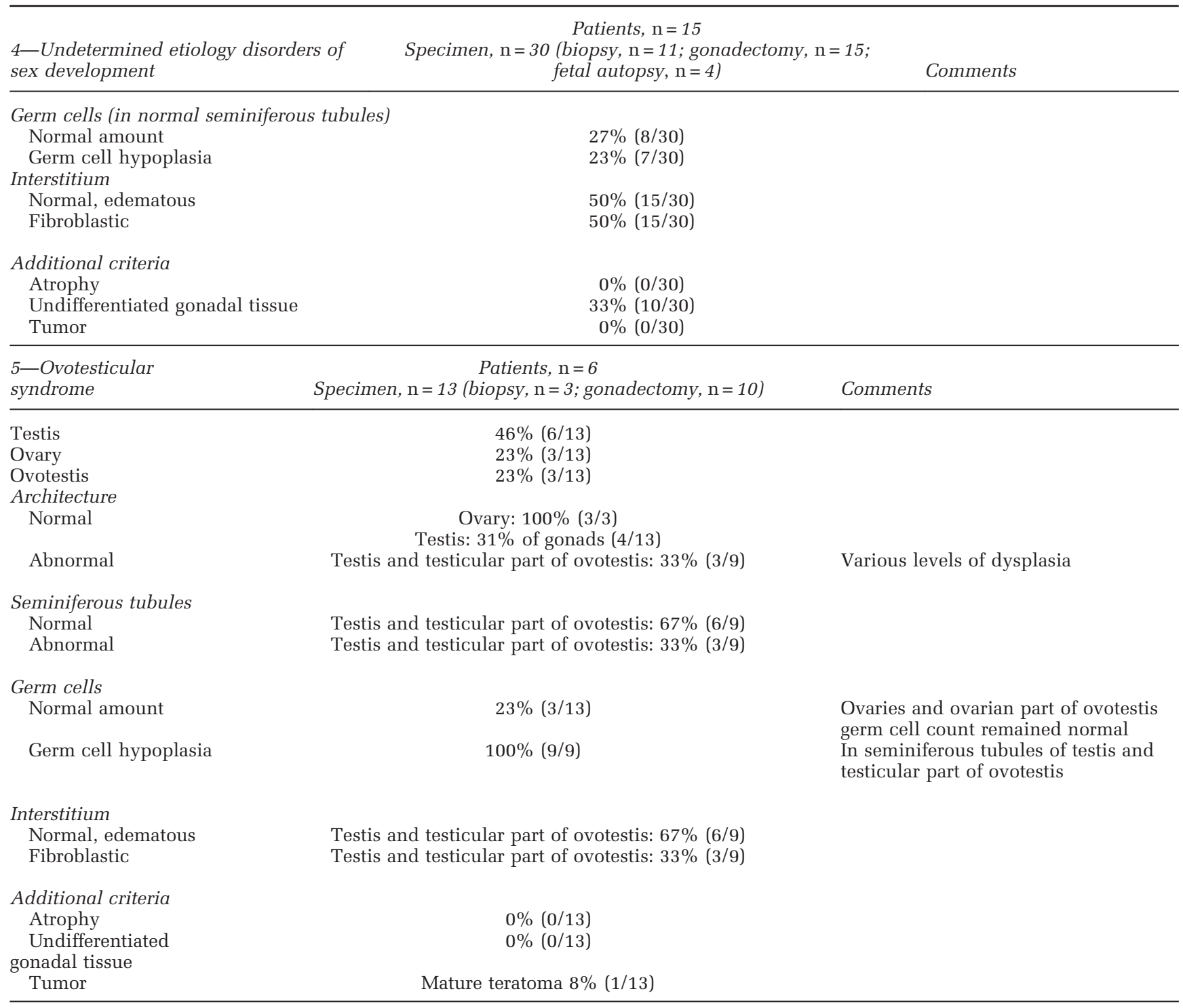

In most cases of bilateral gonadectomy, the aspect of the gonads was symmetrical: bilateral normal testis $(2 / 17,12 \%)$, bilateral hypoplastic testis $(5 / 17,30 \%)$, bilateral testis with dysplasia $(3 / 17,18 \%)$, and bilateral tumor $(4 / 17,24 \%)$. Normal testis+focal dysplasia $(1 / 17,6 \%)$ and testis with dysplasia+tumor $(2 / 17,12 \%)$ also occurred.

The histological features varied depending on the etiology. The pathological analysis of the gonads of 3 patients carrying an SF1 mutation revealed hypoplastic testis without seminiferous tubules disorganization (at 12, 16, 72, and 92 months old). Among the 3 patients carrying a SOX9 abnormality, 1 fetus $(20 \mathrm{GW}+6)$ with a $S O X 9$ mutation presented with normal testes for gestational age, and 2 patients with a SOX9 promoter deletion harbored abnormal testes: 1 with moderate testicular dysplasia (4 months old) and 1 with bilateral severe testicular dysplasia and gonadoblastoma (117 months old). Three older patients with feminine phenotype were managed urgently due to an acute abdominal tumor syndrome. Two of them carried SRY mutations and the third carried a $D A X 1$ duplication. The bilateral gonadectomy revealed malignant germ cell tumors on the left side and a streak gonad with gonadoblastoma on the right side. Two fetuses with POMT2 mutation (23 $\mathrm{GW}+5,27 \mathrm{GW}+3$ ) harbored very immature gonads with sex cords, scarce stretches of seminiferous tubules, and gonadoblastoid cribriform structures containing hyaline material without calcifications. Six patients were diagnosed with WT1 abnormalities. Four of them carried testes with normal or subnormal aspect. One case of Denys-Drash syndrome, who died soon after birth, displayed testicular dysplasia (severe with gonadoblastoma on the left gonad and moderate on the right gonad). The 

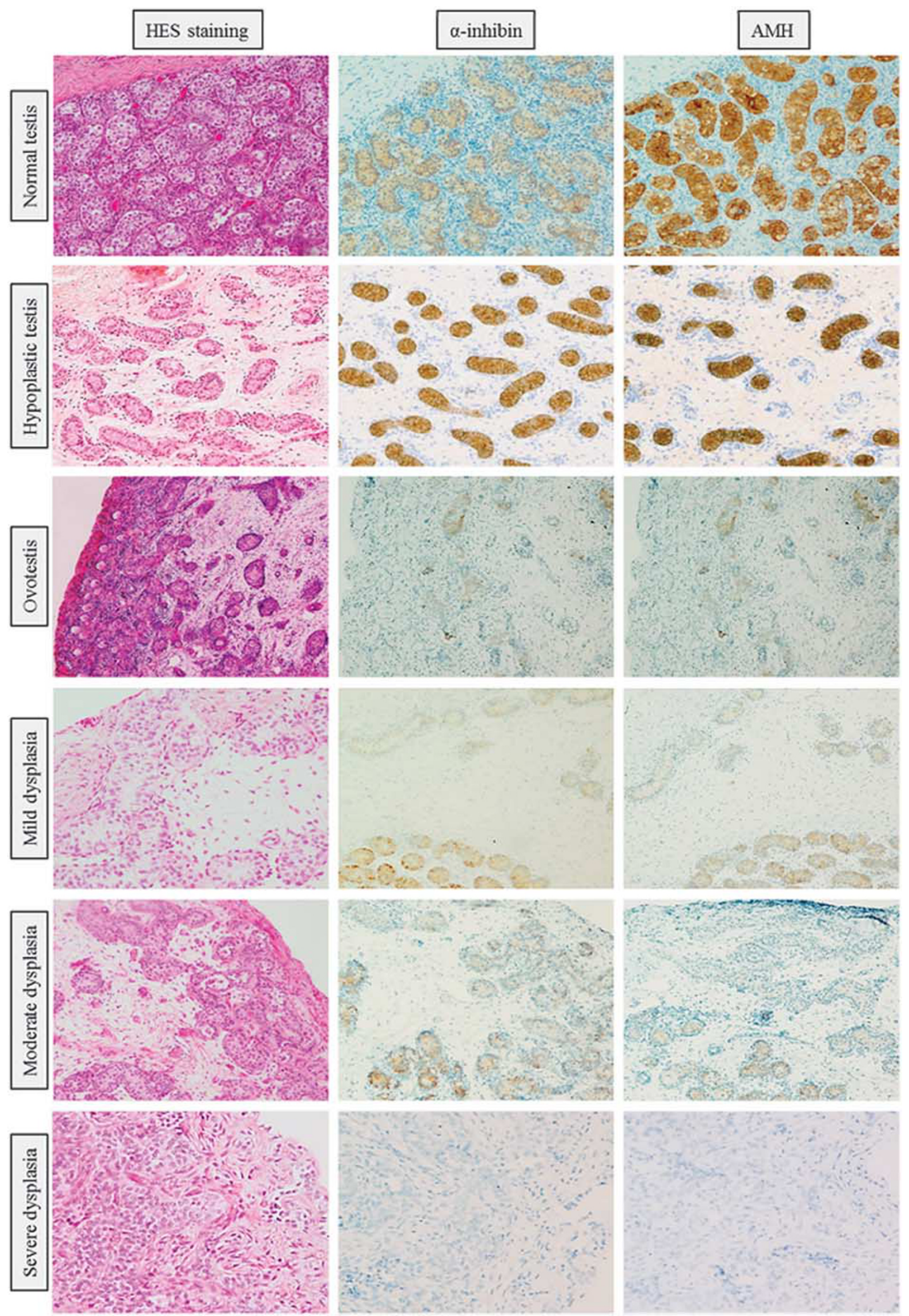
sixth patient underwent bilateral gonadectomy at 26 months old, and presented with bilateral testicular dysplasia: severe with gonadoblastoma on the left side and moderate on the right side.

Germ cell hypoplasia increased with age; indeed, it was moderate on the gonadal biopsy of a 72-month-old patient and severe on the excised gonads at 92 months old. Undifferentiated gonadal tissue was observed at all ages: antenatally (4/6, 66\%), from 0 to 6 months old $(3 / 10,30 \%)$, from 24 to 48 months old $(1 / 2,50 \%)$, over 110 months old $(3 / 8,38 \%)$. Undifferentiated gonadal tissue was, in contrast, always associated with dysplasia.

The immunohistochemical study, performed on 26 samples, displayed a decreased expression of $\alpha$-inhibin and $\mathrm{AMH}$ in the areas of dysplasia, sometimes with a gradient pattern from a better conserved hilar area to a branched tubules peripheral area. A-inhibin and $\mathrm{AMH}$ were not expressed in severe testicular dysplasia, undifferentiated gonadal tissue, or streaks. The expression of CD117 and OCT4 was observed in germ cells that were centrally located in normal seminiferous tubules (6/26, from 0.2 to 92 months old), and in dysplastic tubules, undifferentiated gonadal tissue, gonadoblastoma, and germ cell tumors.

\section{Group 3: Sex Chromosome Mosaicisms/Mixed Gonadal Dysgenesis}

This group included 35 samples from 18 patients between $23 \mathrm{GW}+4$ and 158 months old. No patient underwent iterative biopsies of the same gonad at different ages (Table 4-3). Karyotypes were 45,X0/46, $\mathrm{XY}(14 / 18,78 \%), 45, \mathrm{X0} / 8 \%$ derY $(1 / 18,6 \%), 45$, $\mathrm{X0} / 46$,XY dup tel Y (SRY+) (1/18, 6\%). Different types of gonads were identified: normal testis 1/35 (3\%), hypoplastic testis $3 / 35(9 \%)$, testis with dysplasia: mild 8/35 (23\%), moderate 3/35 (9\%), severe 6/35 (17\%), and streak 14/35 (40\%). Seventeen patients underwent bilateral gonadectomy, and each of them presented with asymmetrical gonads with various changes in at least one gonad: streak +testicular dysplasia (8/17, 47\%) (mild 5/17 (29\%), moderate $2 / 17(12 \%)$, severe $1 / 17(6 \%))$; streak +hypoplastic testis (1/17, 6\%); bilateral streaks (2/17, 12\%); normal or hypoplastic testis+testicular dysplasia (3/17, 18\%) (mild 1/17 (6\%), moderate $1 / 17(6 \%)$, severe $1 / 17(6 \%))$; asymmetrical bilateral dysplasia (3/17, 18\%) (mild+severe 2/17 (12\%), moderate+severe 1/17 (6\%)). Most unilateral streaks involved the left gonad (7/9, 78\%). Undifferentiated gonadal tissue was observed at all ages: antenatal period $(1 / 4,20 \%)$, from 0 to 6 months old $(10 / 16$, $63 \%$ ), from 6 to 12 months old $(3 / 6,50 \%)$, from 36 to 72 months old $(1 / 5,20 \%)$, over 72 months old $(2 / 2,100 \%)$. Undifferentiated gonadal tissue was associated with severe testicular dysplasia (6/6, $100 \%)$ and streaks $(11 / 14,79 \%)$ but it was never observed in normal or hypoplastic testes or with mild or moderate dysplasia. Only 1 patient (158 months old) presented with bilateral streak gonads containing bilateral gonadoblastoma. The immunohistochemical study was performed on 34 samples and underlined a decreased expression of $\alpha$-inhibin and AMH with a spectrum: diffuse and moderate expression in normal and hypoplastic testes, weak or absent in severe testicular dysplasia, and absent in streaks. Within the same gonad, areas with normal testicular architecture were stained whereas disorganized tubules were not. CD117 and OCT4 staining highlighted immature germ cells in severe testicular dysplasia and in undifferentiated gonadal tissue areas.

\section{Group 4: Undetermined Etiology Disorders of Sex Development}

This group included 30 samples from 15 patients from 27 GW to 204 months old (Table 4-4). Karyotypes were 46,XY (11/15, 73\%), 46,XX (1/15, $7 \%)$, or unknown $(4 / 15,7 \%)$. Different types of gonads were observed: normal testis $(8 / 30,27 \%)$, hypoplastic testis $(7 / 30,23 \%)$, and testis with dysplasia $(7 / 30,23 \%)$ : mild $(2 / 30,7 \%)$, moderate $(1 / 30,3 \%)$, severe $(4 / 30,13 \%)$, and streak $(8 / 30$, $27 \%$ ). When bilateral samples were available in this group, the gonadal status was either symmetrical or asymmetrical: bilateral testis (normal or with germ cell hypoplasia) $(4 / 11,36 \%)$, bilateral dysplastic testis $(1 / 11,9 \%)$, bilateral streak $(2 / 11,18 \%)$, normal or hypoplastic testis+dysplastic testis $(2 / 11,18 \%)$, normal or hypoplastic testis+streak $(2 / 11,18 \%)$. As observed in the previous groups, germ cell hypopla-

Figure 1 Morphological aspects and immunohistochemical profile with $\alpha$-inhibin and AMH antibodies of normal testis, testis with germ cell hypoplasia, testis with mild, moderate, and severe dysplasia, and ovotestis. Normal testis: right gonad of a 3-week-old patient with complete androgen insensitivity syndrome; testis with germ cell hypoplasia: right gonad of a 6-month-old patient, undetermined etiology; ovotestis: right gonad of a 4-month-old patient, 46,XX,SRY-; mild dysplasia: left gonad of a 66-month-old patient with 45,X0/46,XY sex chromosome mosaicism; moderate dysplasia: left gonad of a 3-month-old patient with WT1 mutation; severe dysplasia: right gonad of a 1 week-old patient with undetermined etiology disorder of sex development. A-inhibin and AMH are uniformly and strongly expressed in regular seminiferous tubules. However, they are expressed with a lesser intensity in case of alcoholic instead of formalin fixation. In case of an architectural disorganization of the seminiferous tubules (dysplasia), the expression of $\alpha$-inhibin and AMH decreases, parallel to the increasing degree of this disorganization. There is a noticeable difference of staining intensity of the seminiferous tubules in mild and moderate dysplasia, between the tubules in the external part of the gonad (dysplastics) and the hilar part of the gonad (in which the tubules retain a better architecture). 


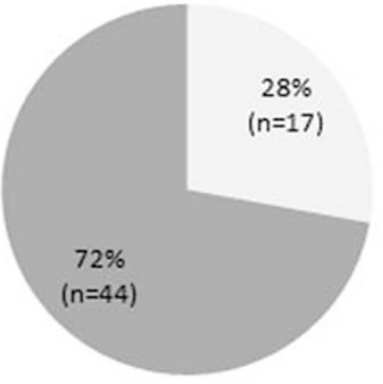

46, $\mathrm{XY}$ disorders of sex development with disorders in androgen synthesis or action $(n=61)$

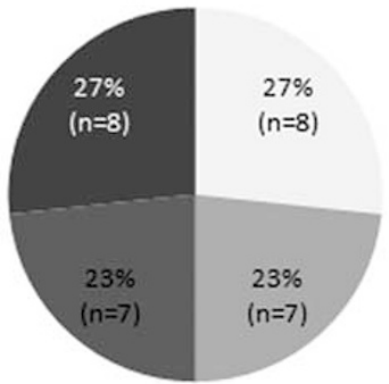

Undetermined etiology disorders of sex development $(n=30)$

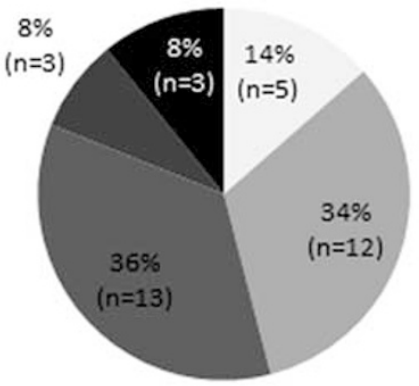

$46, X Y$ disorders of sex development with disorders of gonadal development $(n=36)$

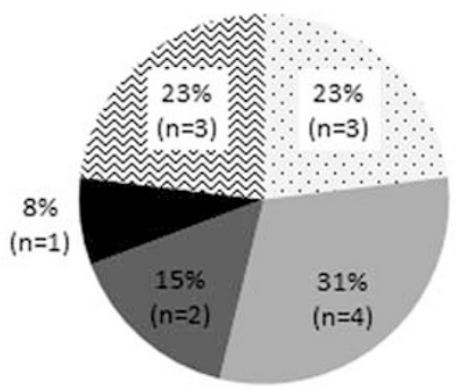

Ovotesticular syndrome $(n=13)$

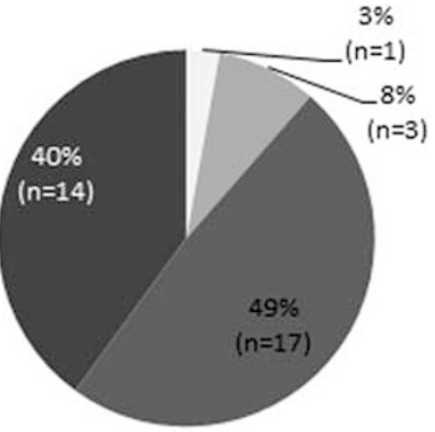

Sex chromosome mosaicism /mixed gonadal dysgenesis $(n=35)$

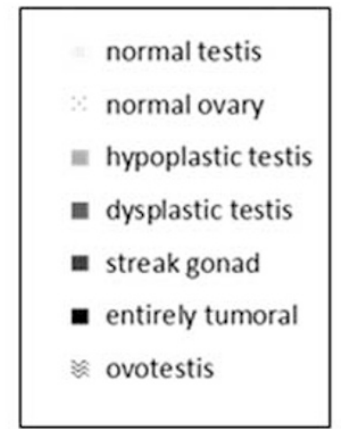

Figure 2 Distribution of the different gonadal subtypes in the study groups based on the Lawson Wilkins Paediatric Endocrine Society/ European Society for Paediatric Endocrinology classification consensus.

sia increased with age: no gonad displayed a normal number of germ cells (more than 60 germ cells per 50 tubular sections) over 20 months old. Undifferentiated gonadal tissue was observed at all ages: prenatally $(2 / 4,50 \%)$, from 0 to 6 months old $(3 / 10$, $30 \%)$, from 12 to 24 months old $(2 / 7,29 \%)$, from 24 to 48 months old $(1 / 3,33 \%)$, from 48 to 110 months old

$(1 / 1,100 \%)$, over 110 months old $(1 / 5,20 \%)$. Undifferentiated gonadal tissue was only associated with moderate or severe dysplasia $(5 / 5,100 \%)$ and streaks $(5 / 8,63 \%)$. The immunohistochemical study, performed on 22 samples, confirmed the normal expression of $\alpha$-inhibin and AMH in normal or hypoplastic testes. However, when seminiferous tubules displayed an abnormal architecture, this expression decreased proportionally. OCT4 and CD117 expression was observed in 9/22 cases (41\%): germ cells centrally located in normal seminiferous tubules in 2 patients (30 GW and 6 months old), in dysplasia areas (7 cases) and in undifferentiated gonadal tissue (2 cases). One patient underwent an excision of the left streak gonad at 20 months old. The right gonadal biopsy performed at the same time showed a normal testis. A second right gonadal biopsy was performed at 73 months old and showed severe testicular dysplasia with undifferentiated gonadal tissue and a positive CD117 and OCT4 staining. This patient developed a mixed germ cell tumor (seminoma and yolk sac tumor) in the right gonad, which was excised at 242 months old.

\section{Group 5: Ovotesticular Syndrome}

This group included 13 samples collected from 6 patients aged from 0.3 to 22 months old. Karyotypes were 46,XX (4/6) and 46,XX SRY+ (2/6) (Table 4-5).

Gonadal histology demonstrated hypoplastic testis (4/13, 31\%), dysplastic testis $(2 / 13,15 \%)$, normal ovary $(3 / 13,23 \%)$, ovotestis $(3 / 13,23 \%)$, and teratoma $(1 / 13,8 \%)$. The gonads were asymmetrical: testis+ovary $(2 / 6,33 \%)$, testis+teratoma $(1 / 6,17 \%)$, testis+ovotestis $(2 / 6,33 \%)$, ovary+ovotestis (1/6, $17 \%)$. The albuginea appeared thick around most of the testes, whereas it appeared thin, irregular, scalloped and covered by an epithelial layer above the disorganized tubules areas. There was no capsule around the ovaries or the ovarian parts of ovotestis. The aspect of the ovaries and the ovarian parts of ovotestis were normal, whereas the testes and the testicular parts of ovotestis displayed germ cell 
hypoplasia $(9 / 9,100 \%)$, edematous stroma (3/9, $33 \%$ ), and dysplasia with branched irregular seminiferous tubules (focally in $2 / 9,22 \%$, and involving all the peripheral area in $1 / 9,11 \%$ ). No undifferentiated gonadal tissue was observed. One gonad (left side) showed a mature teratoma $(1 / 13,8 \%)$. The immunohistochemical study, performed on 5 samples, confirmed the decreased expression of $\alpha$-inhibin and $\mathrm{AMH}$ in the disorganized tubules areas, and the expression of CD117 and OCT4 in 2 samples (at 0.3 and 4 months old).

\section{Discussion}

Different types of gonads have been formerly described in cases of disorders of sex development, but without consistent approach. ${ }^{5,20,21}$ The characterization of gonads in disorders of sex development has never been exclusively histological, and is independent from genetic or phenotypic data. ${ }^{6}$

It makes sense to classify disorders of sex development on karyotype or genetic abnormalities. However, the classification of the Lawson Wilkins Paediatric Endocrine Society and the European Society for Paediatric Endocrinology has its limits. It identifies several 'ovotestis' groups, corresponding to different karyotypes (46,XX, 46,XY, sex chromosome mosaicism) or genetic abnormalities (DAX1 duplication...). This classification also uses the term 'dysgenesis' to describe either clinical or hormonal or histological features. 'Dysgenesis' is defined as an anomaly of the development of an organ. This definition covers a large spectrum of histological lesions, from organ agenesis to very subtle architectural changes. The term 'dysgenesis' itself is therefore very ambiguous and refers in the literature to both morphological and functional abnormalities, defined with variable criteria and with various interpretations. For some authors, gonadal dysgenesis is a syndrome associating 46, $\mathrm{XY}$ karyotype, sexual ambiguity with Mullerian remnants, high follicle-stimulating hormone, low anti-Mullerian hormone levels, ${ }^{22}$ low level of testosterone, and increased testosterone precursors after human chorionic gonadotropin stimulation. ${ }^{23}$ If those results suggest a testicular malfunction, they are not linked to objective histological features. Skakkebaek et al ${ }^{24}$ consider the 'testicular dysgenesis syndrome' as a very broad pathological framework, including a decrease of fertility because of lower sperm quality, cryptorchidia, hypospadias, and an increased risk of testicular cancer. This syndrome may be linked to a disruption of the embryonic and fetal gonadal differentiation program, and would imply genetic abnormalities as well as endocrinal environmental factors. Abnormal maturation of Sertoli cells would result in hypoplastic seminiferous tubules called 'dysgenetic tubules', which are isolated or in clusters, layered by a pseudostratified epithelium with a narrow lumen and a thickened basal membrane, usually containing few germ cells, spermatogonia, microcalcifications, or even germ cell neoplasia in situ. ${ }^{24,25}$ 'Dysgenetic' Sertoli cells would have an elongated nucleus with small nucleoli, abnormally located in the cytoplasm. 'Dysgenetic tubules' would be considered immature when $\mathrm{CK} 18^{26}$ would be expressed. However, all these lesions are not specific to an organogenesis disorder and tend to be closer to a 'dedifferentiation' of Sertoli cells after an initial normal gonadal development, leading to masculine infertility disorders. ${ }^{27}$ Ribeiro Scolfaro defined 'gonadal dysgenesis' as a modification of the mean diameter of the tubules, with a decreased number of Sertoli cells by tubule and a decrease of the tubular fertility index. Tubules would occasionally be surrounded by fibrosis. Patients would present with hypospadias, bilateral cryptorchidia, and Mullerian remnants. 'Dysgenetic gonads' would also present with poorly differentiated seminiferous tubules, surrounded by an interstitium resembling the ovarian stroma. ${ }^{23}$ Finally, some authors described 'dysgenetic gonads' as a network of badly organized and branched seminiferous tubules arranged in an abnormal fibrous stroma which are surrounded by a thinned albuginea, layered by cells resembling those covering the normal ovary. ${ }^{20,23,28,29}$ In his histological study of Denys-Drash syndrome's gonads, Jaubert ${ }^{30}$ used the very same description and observed testes with variable aspects, from dysgenetic to normal testis. This notion of 'morphological spectrum' is also used by Cools et $a l^{31}$ for gonads of the groups 'Sex chromosome disorders of sex development' and '46,XY gonadal dysgenesis' in the Lawson Wilkins Paediatric Endocrine Society/European Society for Paediatric Endocrinology classification.

Like Cools et al, ${ }^{7}$ we consider gonadal dysgenesis as an embryologic abnormality of the gonad (incomplete or abnormal formation) due to an abnormal germ cell migration and/or organization in the genital ridge. Dysgenesis is the result of an intrinsic disorder of gonadal development, with morphological and functional consequences which are more or less noticeable. ${ }^{32}$ Gonadal dysgenesis is, therefore, either linked to a chromosomal abnormality, or to mutation of one of the numerous genes involved in the urogenital ridge formation and sexual determination of the undifferentiated gonad. It must be distinguished from hypo- or hypervirilization syndromes of hormonal origin, affecting the sexual phenotype, where the initial gonadal formation is normal. The term dysplasia should then be favored to describe abnormal features of testis architecture, by analogy with renal dysplasia which describes histological features related to a renal development disorder regardless of its etiology. The term 'dysplasia' purely describes histological features irrespective of clinical, hormonal, or genetic data. These histological statements should then be correlated in a second stage with the clinical and paraclinical data. 
Normal or hypoplastic testis represented $58 \%$ of the studied gonads and were present in every group (Figure 2) with a heterogeneous distribution: they represented $100 \%$ of gonads in the $46, \mathrm{XY}$ disorders of sex development with disorders in hormonal synthesis or action group, but only $47 \%$ in the 46 , $\mathrm{XY}$ disorders of sex development with disorders of gonadal development group, $11 \%$ in sex chromosome mosaicisms/mixed gonadal dysgenesis group, $31 \%$ in ovotesticular disorders of sex development group, and $50 \%$ in the undetermined etiology disorders of sex development group. Ovaries were encountered in the ovotesticular syndrome group: they represented a minimal fraction of the examined samples $(3 / 175,2 \%)$ and were normal in aspect. Hypoplastic testis presented with a thick and regular albuginea. Their interstitium was reduced, edematous or seldom fibro-edematous. Seminiferous tubules were always regular but their lamina propria was thickened after the age of puberty. Germ cell hypoplasia tended to worsen with age. Post pubertal testes showed severe hypospermatogenesis with an incomplete maturation and very rare spermatids and no spermatozoa, thus suggesting important hypo fertility at an adult age, especially as most of the testes were in the extra scrotal position. The immunohistochemical pattern of the normal or hypoplastic testes was in accordance with the literature: ${ }^{33}$ no previous publication underlined a decreased expression of $\mathrm{AMH}$ on prepubertal patients with a 'hormonal' disorder (except in case of anti-Mullerian hormone mutation).

Dysplastic gonads were seen in $22 \%$ of all examined gonads. If normal or hypoplastic testes were observed in each group, dysplasia features were only present in 'gonadal dysgenesis' subtypes: 46,XY disorders of sex development with disorders of gonadal development (13/36, 36\%), sex chromosome mosaicism/mixed gonadal dysgenesis (17/35, 49\%), and undetermined etiology disorders of sex development $(7 / 30,23 \%)$, but were never present in case of hormonal deficiency (Figure 2). Dysplasia was observed at any age in those groups, and exhibited different levels of severity: mild (6/25 from 0 to 6 months old, 1/4 from 12 to 24 months old, 1/5 from 48 to 110 months old); moderate ( $1 / 9$ prenatally, $7 / 25$ from 0 to 6 months old, $1 / 3$ from 24 to 48 months old); severe (5/9 prenatally, 7/25 from 0 to 6 months old, $1 / 3$ from 24 to 48 months old, $1 / 5$ from 48 to 110 months old, 2/10 over 110 months old). Dysplasia was always focal, and the whole spectrum of dysplasia could be observed within the same gonad (Figure 3).

Therefore, 'dysplasia' appeared as the morphological parameter of a development disorder of the testis which results in architectural abnormalities of the seminiferous tubules, the albuginea and the interstitium: dysplasia is the reflection of an intrinsic development disorder, variable in severity and it could be aggravated by environmental factors (such as cryptorchidia). On the contrary, 'hypoplasia' reflects a lack of maintenance of germ cells and/or gonadal function, and not an organization defect. The absence of the constitution of a thick and regular albuginea appears in our study as a common feature in dysplastic testes, and could be the reflection of a masculinization defect of the gonad. ${ }^{32}$ However, the presence of isolated seminiferous tubules in the albuginea is not a pathognomonic feature of gonadal dysgenesis and may be observed in cryptorchidia. ${ }^{34}$ Its association with interstitium changes should suggest mild dysplasia. A-Inhibin and AMH stainings also reflect the severity of dysplasia. Indeed, in normal testes, whatever the age and their location (intrascrotal or cryptorchid), Sertoli cells always express $\alpha$-inhibin. ${ }^{35}$ Conversely a loss of expression of $\alpha$-inhibin and AMH in dysplastic areas was observed in our series (Figure 4). To the best of our knowledge, such a loss of expression in irregular seminiferous tubules has never been reported in literature. Rey et $a l^{33}$ underlined the presence of AMH staining on the immunohistochemical study of gonads from patients with intersex disorders, despite low plasmatic anti-Mullerian hormone levels. Cools et $a l^{4}$ reported a normal AMH expression in disorganized testicular areas. Furthermore, this study showed the expression of CD117 and OCT4 GC immaturity markers by some germ cells in dysplastic areas, as Cools et $a l^{7}$ identified in undifferentiated gonadal tissue, revealing a neoplastic potential.

Streak gonads are defined by a fibroblastic interstitium without follicles or by a persisting tubular structure. The term 'fibroblastic' interstitium should be preferred to 'ovarian' to avoid any confusion with the totally independent histological structure of the ovotestis. Streak gonads represented $14 \%$ of our samples. They were present at any age (prenatally $3 / 9$, from 0 to 6 months old 5/25, from 12 to 24 months old $3 / 4$, from 24 to 48 months old $1 / 3$, from 48 to 110 months old 3/5, over 110 months old 8/10) but, as dysplastic features, they were only noticed in the groups 46,XY disorders of sex development with disorders of gonadal development, sex chromosome mosaicism/mixed gonadal dysgenesis, and undetermined etiology disorders of sex development (Figure 2). We consider streak gonad as the terminal form of dysplasia, but we decided to keep this term as it is commonly used in literature.

A correlation between undifferentiated gonadal tissue, moderate and severe testicular dysplasia, and streak gonads, has been shown in the 'gonadal dysgenesis' groups (46,XY disorders of sex development with disorders of gonadal development, sex chromosome mosaicism/mixed gonadal dysgenesis, undetermined etiology disorders of sex development) (Figure 5). Undifferentiated gonadal tissue was present in $33 \%$ testes with moderate dysplasia (3/9), 100\% testes with severe dysplasia (19/19), and $67 \%$ streak gonads (16/24). However, it was not observed in normal testes (31 cases), hypoplastic testes (72 cases), or mild dysplasia (8 cases). These 


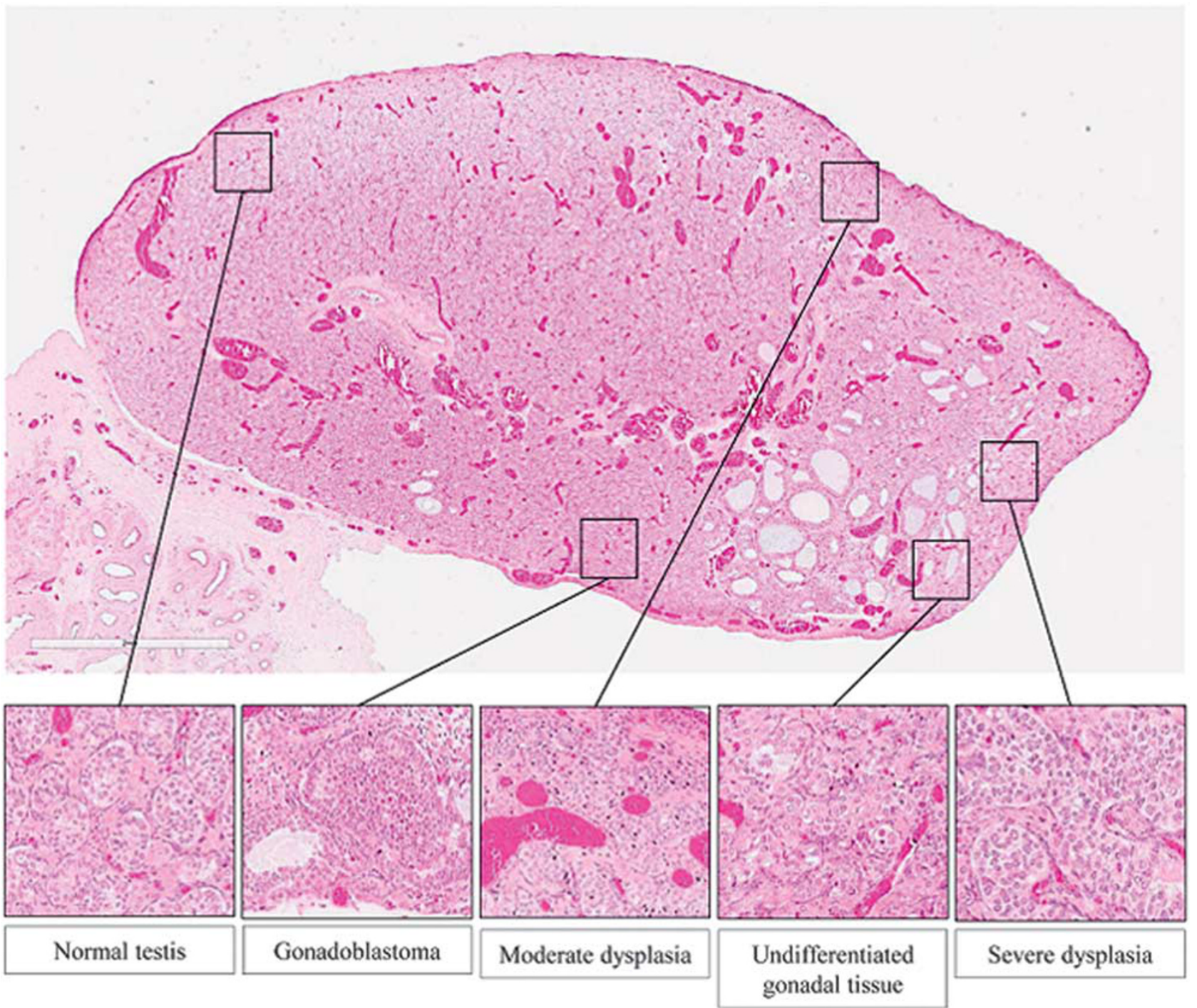

Figure 3 Illustration of the coexistence of multiple histological features from the dysplastic spectrum on a single gonad. Low magnification of the right-side gonad of a 6-day-old patient carrying a WT1 mutation (Denys-Drash syndrome). The gonad appears irregular in shape. The histological analysis reveals several degrees of testicular dysplasia, undifferentiated gonadal tissue, as well as a focus of gonadoblastoma, next to normal testicular tissue. The normal testicular tissue presents with regular round seminiferous tubules disposed in an interstitium of little abundance. Other areas of the gonad harbor dysplasia: mild with tubules abnormally branched located under the testicular albuginea, separated from the hilar part of the testis by an edematous gap; moderate with abnormally branched tubules disposed into a fibro-edematous interstitial tissue; severe with anastomotic tubules in a fibrous interstitium, without lobular pattern on low magnification. The undifferentiated gonadal tissue is characterized by germ cells within immature sex cords and isolated in the interstitium. Gonadoblastoma is identified as nests of germ cells and Sertoli-like cells with hyaline material within their lumens.

data suggest that undifferentiated gonadal tissue is part of the testicular dysplasia spectrum and would correspond to an extreme form of dysplasia, with a rough testicular differentiation. Thus, the identification of moderate or severe dysplasia in a testicular biopsy is highly suggestive of foci of undifferentiated gonadal tissue in this gonad with a potential tumor risk. The neoplastic risk of undifferentiated gonadal tissue is not definite. ${ }^{4,9}$ To assess it, it is necessary to establish the presence or the absence of residual germ cells and to underline their immature features with immunomarkers (OCT4 or TSPY). ${ }^{2,7,8}$ The only gonad without any tumor risk would be the 'complete' streak gonad, entirely fibrous and without remaining germ cell; however, this diagnosis can only be done after a histological examination of the whole gonad, and not on a single biopsy.

A cluster of immature germ cells may evolve into gonadoblastoma; however, not all gonadoblastoma would lead to a malignant germ cell tumor: ${ }^{18,36}$ in some cases, the germ cells of the gonadoblastoma do not persist: the gonad would then appear germ cell-free and filled with nodular calcifications, the so-called 'burnt-out gonadoblastoma' in the literature. Thus the progressive risk of undifferentiated gonadal tissue to evolve into gonadoblastoma or into 


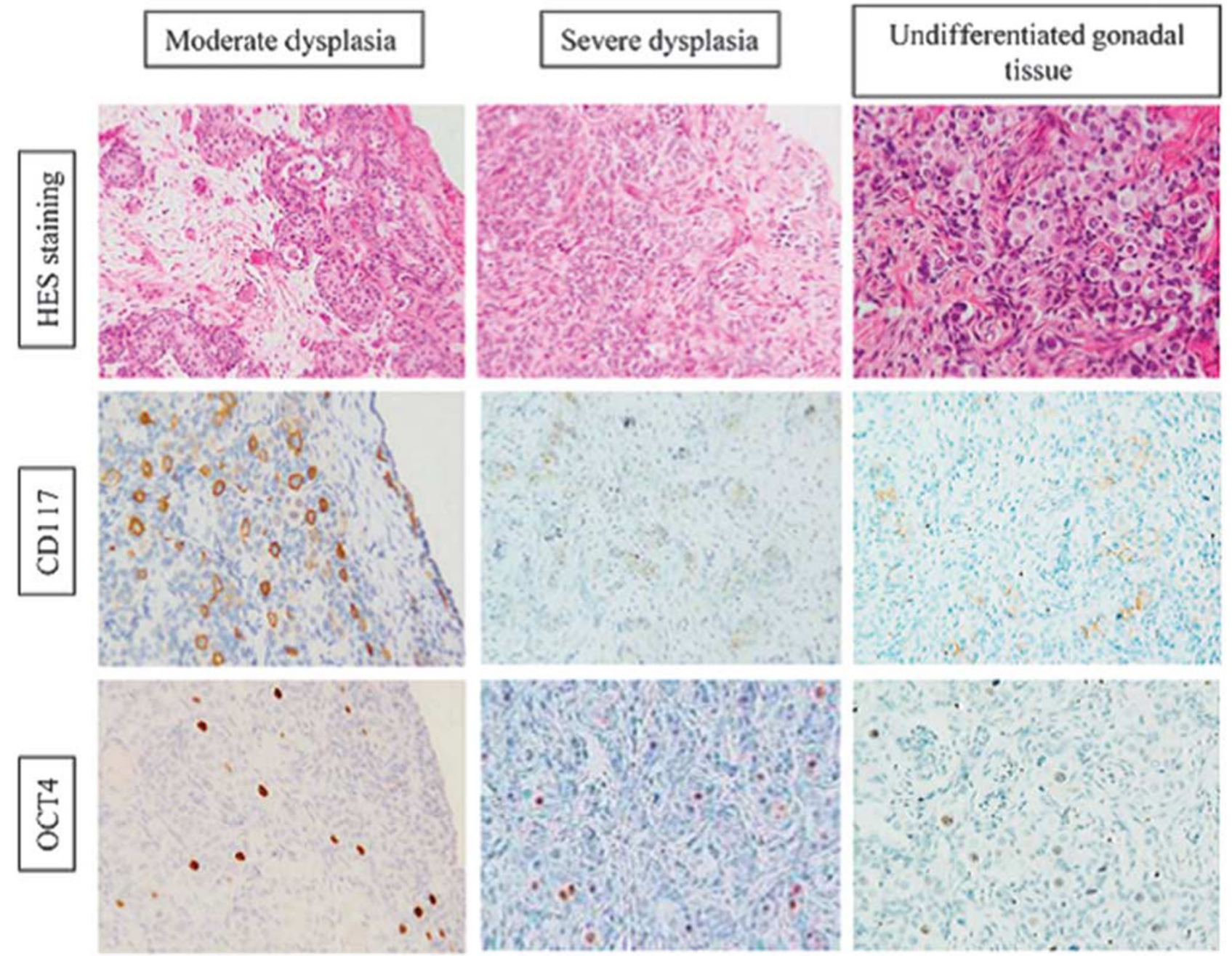

Figure 4 Histology and immunohistochemical profile with CD117 and OCT4 germ cell immaturity markers of gonads with moderate and severe dysplasia and with undifferentiated gonadal tissue. Moderate dysplasia: left gonad of an 8-month-old patient with 45,X0/46,XY sex chromosome mosaicism; severe dysplasia: right gonad of a 117-month-old patient with SOX9 promoter deletion; undifferentiated gonadal tissue: left gonad of a 3-month-old patient with 45,X0/46,XY sex chromosome mosaicism. Dysplastic gonads display an increasing disorganization of seminiferous tubules, as well as modifications of the stroma which becomes more abundant and fibrous. Germ cells located inside the branched seminiferous tubules of dysplastic areas show an abnormal expression of immaturity germ cells markers (over the age of 6 months old). In undifferentiated gonadal tissue, many germ cells randomly disposed in the stroma express CD117 and OCT4.

a malignant germ cell tumor could be compared with the evolutive risk of renal nephrogenic rests into nephroblastoma by Beckwith. ${ }^{37}$

Aaronson and Aaronson ${ }^{5}$ recently suggested to use the term 'intersex syndromes', rather than the term 'disorders of sex development'. They proposed a classification of four groups based on histological features: ovarian, ovotesticular, testicular and dysgenetic disorders of sex development. However, this histological classification appears incomplete and does not assess either the malignant risk of evolution, or the histological spectrum. It appears fundamental to our team to hold on to the Lawson Wilkins Paediatric Endocrine Society/European Society for Paediatric Endocrinology classification etiologic groups to retain a rational reflection on the management of patients.
This study represents the first analysis of gonads with a broad spectrum of disorders of sex development. It gathers a cohort of 175 cases which is, to our knowledge, the largest published histological study of gonads of disorders of sex development to date. It provides reproducible histological guidelines to describe gonads, independently of chromosomal, biological, or molecular data. The accurate morphological and immunohistochemical criteria allow a simple histological classification in 5 subtypes. These results demonstrated that no group of the Lawson Wilkins Paediatric Endocrine Society/European Society for Paediatric Endocrinology consensus classification corresponds to a specific histological phenotype and more especially that normal or hypoplastic testes may occur in each group. Conversely, dysplasia was only observed in 


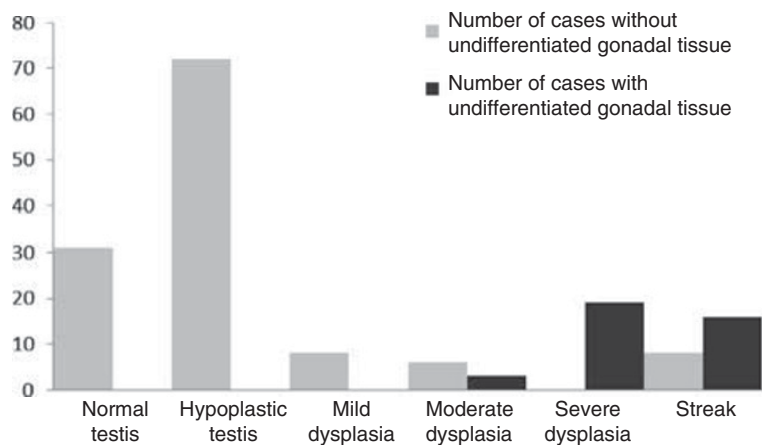

Figure 5 Illustration of the association of undifferentiated gonadal tissue with different histological subtypes. Undifferentiated gonadal tissue is never encountered either within normal or hypoplastic testis or in case of mild dysplasia. However, it is associated with moderate and severe dysplasia, as well as streak gonads.

chromosomal or genetic groups of disorders of sex development: 46,XY disorders of sex development with disorders of gonadal development, and sex chromosome mosaicism/mixed gonadal dysgenesis. This original entity is the histological reflection of dysgenesis, and its neoplastic potential should be taken into account. Lesions of the dysplasia spectrum, including undifferentiated gonadal tissue as its most severe degree, are focal: a biopsy with normal histological testicular tissue does not exclude the presence of dysplasia in another area of the gonad.

\section{Acknowledgments}

We acknowledge Coline Sgorbini for language assistance.

\section{Disclosure/conflict of interest}

The authors declare no conflict of interest.

\section{References}

1 Hughes IA, Houk C, Ahmed SF, et al. Lawson Wilkins Pediatric Endocrine Society/European Society for Paediatric Endocrinology Consensus Group. Consensus statement on management of intersex disorders. J Pediatr Urol 2006;2:148-162.

2 Cools M, Drop SL, Wolffenbuttel KP, et al. Germ cell tumors in the intersex gonad: old paths, new directions, moving frontiers. Endocr Rev 2006;27:468-484.

3 Hersmus R, de Leeuw BH, Wolffenbuttel KP, et al. New insights into type II germ cell tumor pathogenesis based on studies of patients with various forms of disorders of sex development (DSD). Mol Cell Endocrinol 2008;291: $1-10$.

4 Cools M, Looijenga LH, Wolffenbuttel KP, et al. Disorders of sex development: update on the genetic background, terminology and risk for the development of germ cell tumors. World J Pediatr 2009;5:93-102.
5 Aaronson IA, Aaronson AJ. How should we classify intersex disorders? J Pediatr Urol 2010;6:443-446.

6 Nistal M, Paniagua R, González-Peramato P, et al. Perspectives in pediatric pathology, chapter 5. Gonadal dysgenesis. Pediatr Dev Pathol. 2015;18:259-278.

7 Cools M, Stoop H, Kersemaekers AM, et al. Gonadoblastoma arising in undifferentiated gonadal tissue within dysgenetic gonads. J Clin Endocrinol Metab 2006;91:2404-2413.

8 Dieckmann KP, Skakkebaek NE. Carcinoma in situ of the testis: review of biological and clinical features. Int J Cancer 1999;83:815-822.

9 Crawford JM, Warne G, Grover S, et al. Results from a pediatric surgical centre justify early intervention in disorders of sex development. J Pediatr Surg 2009;44: 413-416.

10 Wiesemann C, Ude-Koeller S, Sinnecker GH, et al. Ethical principles and recommendations for the medical management of differences of sex development (DSD)/intersex in children and adolescents. Eur J Pediatr 2010;169:671-679.

11 de Jong J, Stoop H, Dohle GR, et al. Diagnostic value of OCT3/4 for pre-invasive and invasive testicular germ cell tumours. J Pathol 2005;206:242-249.

12 Nistal M, Paniagua R, Diez-Pardo JA. Histologic classification of undescended testis. Human Pathol 1980;11:666-674.

13 Johnsen SG. Testicular biopsy score count-a method for registration of spermatogenesis in human testes: normal values and results in 335 hypogonadal males. Hormones 1970;1:2-25.

14 Cools M, van Aerde K, Kersemaekers AM, et al. Morphological and immunohistochemical differences between gonadal maturation delay and early germ cell neoplasia in patients with undervirilization syndromes. J Clin Endocrinol Metab 2005;90:5295-5303.

15 Ramani P, Yeung CK, Habeebu SS. Testicular intratubular germ cell neoplasia in children and adolescents with intersex. Am J Surg Pathol 1993;17:1124-1133.

16 Skakkebaek NE. Carcinoma-in-situ of testis in testicular feminization syndrome. Acta Pathol Microbiol Scand A 1979;87:87-89.

17 Ulbright TM, Amin MB, Balzer B, et al. Germ cell tumours. In: Moch H, Humphrey PA, Ulbright TM, Reuter VE (eds). WHO Classification of Tumours of the Urinary System and Male Genital Organs, 4th edn. International Agency for Research on Cancer: Lyon, 2016, pp 189-227.

18 Beaulieu Bergeron M, Lemieux N, Brochu P. Undifferentiated gonadal tissue, Y chromosome instability, and tumors in XY gonadal dysgenesis. Pediatr Dev Pathol 2011;14:445-459.

19 Kaprova-Pleskacova J, Stoop H, Brüggenwirth $\mathrm{H}$, et al. Complete androgen insensitivity syndrome: factors influencing gonadal histology including germ cell pathology. Mod Pathol 2014;27:721-730.

20 Rutgers JL, Scully RE. Pathology of the testis in intersex syndromes. Semin Diagn Pathol 1987;4:275-291.

21 Nistal M, Garcia-Fernández E, Mariño-Enríquez A, et al. Diagnostic value of the gonadal biopsy in the disorders of sex development. Actas Urol Esp 2007;31:1056-1075.

22 Rey RA, Belville C, Nihoul-Fékété C, et al. Evaluation of gonadal function in 107 intersex patients by means of serum antimüllerian hormone measurement. J Clin Endocrinol Metab 1999;84:627-631.

23 Ribeiro Scolfaro M, Aparecida Cardinalli I, Gabas Stuchi-Perez E, et al. Morphometry and histology 
of gonads from 13 children with dysgenetic male pseudohermaphroditism. Arch Pathol Lab Med 2001;125:652-656.

24 Skakkebaek NE, Rajpert-De Meyts E, Main KM. Testicular dysgenesis syndrome: an increasingly common developmental disorder with environmental aspects. Hum Reprod 2001;16:972-978.

25 Oosterhuis JW, Looijenga LH. Testicular germ-cell tumours in a broader perspective. Nat Rev Cancer 2005;5:210-222.

26 Nistal M, De Mora JC, Paniagua R. Classification of several types of maturational arrest of spermatogonia according to Sertoli cell morphology: an approach to aetiology. Int J Androl 1998;21:317-326.

27 Sharpe RM, McKinnell C, Kivlin C, et al. Proliferation and functional maturation of Sertoli cells, and their relevance to disorders of testis function in adulthood. Reproduction 2003;125:769-784.

28 Berkovitz GD, Fechner PY, Zacur HW, et al. Clinical and pathologic spectrum of $46, \mathrm{XY}$ gonadal dysgenesis: its relevance to the understanding of sex differentiation. Medicine (Baltimore) 1991;70:375-383.

29 Chemes H, Muzulin PM, Venara MC, et al. Early manifestations of testicular dysgenesis in children: pathological phenotypes, karyotype correlations and precursor stages of tumour development. APMIS 2003;111:12-23; discussion 23-24.
30 Jaubert F, Vasiliu V, Patey-Mariaud de Serre N, et al. Gonad development in Drash and Frasier syndromes depends on WT1 mutations. Arkh Patol 2003;65:40-44.

31 Cools M, Pleskacova J, Stoop H, et al. Gonadal pathology and tumor risk in relation to clinical characteristics in patients with 45,X/46,XY mosaicism. J Clin Endocrinol Metab 2011;96:E1171-E1180.

32 Wartenberg H. Der Mesonephros und die Gonadenentwicklung. Verh Anat ges 1979;73:385-401.

33 Rey R, al-Attar L, Louis F, et al. Testicular dysgenesis does not affect expression of anti-müllerian hormone by Sertoli cells in premeiotic seminiferous tubules. Am J Pathol 1996;148:1689-1698.

34 Nistal M, Paniagua R, León L, et al. Ectopic seminiferous tubules in the tunica albuginea of normal and dysgenetic testes. Appl Pathol 1985;3:123-128.

35 Nistal M, González-Peramato P, De Miguel MP. Immunodetection of inhibin in the human testis and epididymis during normal development and in nontumoural testicular lesions. Reprod Fertil Dev 2010;22: $558-563$.

36 Looijenga LH, Hersmus R, Oosterhuis JW, et al. Tumor risk in disorders of sex development (DSD). Best Pract Res Clin Endocrinol Metab 2007;21:480-495.

37 Beckwith JB, Kiviat NB, Bonadio JF. Nephrogenic rests, nephroblastomatosis, and the pathogenesis of Wilm's tumor. Pediatr Pathol 1990;10:1-36. 